\title{
REVIEW OF CURRENT EVIDENCE ON THE IMPACT OF PESTICIDES, POLYCHLORINATED BIPHENYLS AND SELECTED METALS ON ATTENTION DEFICIT / HYPERACTIVITY DISORDER IN CHILDREN
}

\section{KINGA POLAŃSKA, JOANNA JUREWICZ, and WOJCIECH HANKE}

Nofer Institute of Occupational Medicine, Łódź, Poland

Department of Environmental Epidemiology

\begin{abstract}
The aim of this review was to investigate the association between attention deficit / hyperactivity disorder (ADHD) or ADHD-related symptoms and industrial chemicals, such as organophosphates and organochlorine pesticides, polychlorinated biphenyls (PCBs), lead, mercury and manganese. Medline, PubMed and EBSCO searches were performed to identify the studies that analyzed the association of prenatal and postnatal child exposure to such toxicants and ADHD or ADHD-related symptoms. The review is restricted to human studies published in English in peer-reviewed journals since 2000. Most of the presented studies focused on pesticides, PCB and lead. The impact of mercury and manganese was investigated less frequently. The findings indicate that children's exposure to organophosphate pesticides may cause symptoms consistent with pervasive developmental disorder, ADHD or attention problems. Exposures to organochlorine pesticides and PCBs were associated with ADHD-like behaviors such as alertness, quality of alert response, and cost of attention. The studies provided evidence that blood lead level below $10 \mu \mathrm{g} / \mathrm{dl}$ was associated with ADHD or ADHD-related symptoms. Information on the association between exposure to mercury and neurotoxicity is limited, and requires further confirmation in future research. Two studies indicated that exposure to manganese is related to ADHD; such exposure and its impact on children neurodevelopment need to be further investigated. Future studies should use a prospective design with multiple biological samples collected over time for better assessment of exposure and its critical windows. Additionally, inclusion of potential confounding factors and co-exposures is crucial.
\end{abstract}

Key words:

Children, Chemicals, Attention deficit / hyperactivity disorder, Inattention, Impulsivity

\section{INTRODUCTION}

In recent years, increasing awareness has been observed concerning the role of different toxicants in neurodevelopmental disorders, including attention-deficit / hyperactivity disorder (ADHD). Developmentally inappropriate high levels of inattention, impulsivity, and hyperactivity are characteristics of ADHD according to DSM-IV [1-3]. Current ICD-10 uses a different name, hyperkinetic disorder (HD), but it provides very similar symptoms for this disorder [4]. Regardless of the name used, ADHD/HD is one of the most common neurobehavioral disorders in childhood, affecting 3-10\% of children worldwide [1,2].

Received: May 8, 2012. Accepted: July 19, 2012.

This study was performed under the project "Prenatal and postnatal exposure to tobacco smoke, PAHs and heavy metals and the risk of respiratory diseases, allergy and poor mental and physical development" supported by the grant PNRF-218-AI-1/07 from Norway through the Norwegian Financial Mechanism within the PolishNorwegian Research Fund.

Correspondig author: K. Polańska, Nofer Institute of Occupational Medicine, Department of Environmental Epidemiology, św. Teresy 8, 91-348 Łódź, Poland (e-mail: kinga@imp.lodz.pl). 
Symptoms of ADHD often persist into adolescence and adulthood, and are associated with substantial social and medical costs. ADHD is a highly heritable disorder, with pooled data from twin studies suggesting a heritability rate of $76 \%$ [5]. Emerging evidence indicates that neurodevelopmental disorders, including $\mathrm{ADHD}$, result from complex interactions of genetic, environmental, and social factors. The developing brain is uniquely vulnerable to neurotoxins at exposure levels that have no lasting effects on adults. Although public health activities and regulatory initiatives limiting the level of exposure to industrial chemicals are remarkably successful, there are still concerns of their impact, even at low level, on children's health and neurodevelopment.

This paper reviews literature published since 2000 investigating the association between ADHD or ADHD-related symptoms and industrial chemicals, such as organophosphates and organochlorine pesticides, polychlorinated biphenyls (PCBs), heavy metals, and manganese.

\section{Criteria of the selection of studies to the review}

Medline, PubMed and EBSCO searches were performed to identify studies that analyzed the association of prenatal and postnatal children's exposure to industrial chemicals and ADHD or ADHD-related symptoms. Relevant studies were also identified via a review of references cited in published studies. The review is restricted to human studies published in peer-reviewed English journals since 2000. The following keywords were used: ADHD, hyperactivity, inattention, impulsivity, pregnancy, prenatal period, child, environmental exposures, industrial chemicals, organophosphate pesticides, organochlorine pesticides, PCBs, heavy metals, lead, mercury, and manganese. The following information was reviewed from each paper, which met the eligible criteria: study design and population, sources of exposure and methods used for its assessment, methods of assessment of ADHD or ADHD-related symptoms and confounding factors included in analysis.
Out of the total 95 identified articles, 31 met the eligibility criteria and were included in the present review.

\section{Organophosphates pesticides and ADHD or ADHD-related symptoms}

Organophosphate (OP) pesticides are a group of insecticides commonly used for agricultural purposes. OP pesticides are potent toxicants that target the nervous systems of insects and other pests [7]. Exposure to some of these organophosphate compounds was shown to cause hyperactivity and cognitive deficits in animal studies [8]. Recent studies have shown that fetuses and young children have lower levels of detoxifying enzymes (paraoxonase or chlorpyrifos-oxonase) that deactivate OP $[9,10]$ than adults, suggesting that they may be more vulnerable to these exposures.

Several biological mechanisms might cause an association between OP pesticides and ADHD. The primary action of organophosphates, particularly with respect to acute poisoning, is inhibition of acetylcholinesterase [11], and disruptions in cholinergic signaling [12]. At doses lower than those inhibiting acetylcholinesterase, certain organophosphates affect different neurochemical targets, several neurotransmitter and second messenger systems, including growth factors $[13,14]$. Developmental exposure to organophosphates might have persistent effects on multiple neural systems that may cause ADHD behaviors, such as inattention and cognitive deficits, similar to the effects of developmental nicotine exposure $[15,16]$.

The associations between organophosphate pesticides, ADHD and attention-related outcomes were examined in five studies performed in the United States among young children [17-21] (Table 1).

Rauh et al. [17] found that concentrations of chlorpyrifos in maternal serum were consistently associated with the mothers' report of symptoms of pervasive developmental disorder (PDD) as well as that of attention deficit / hyperactivity disorder (ADHD) or attention problems. Mental 


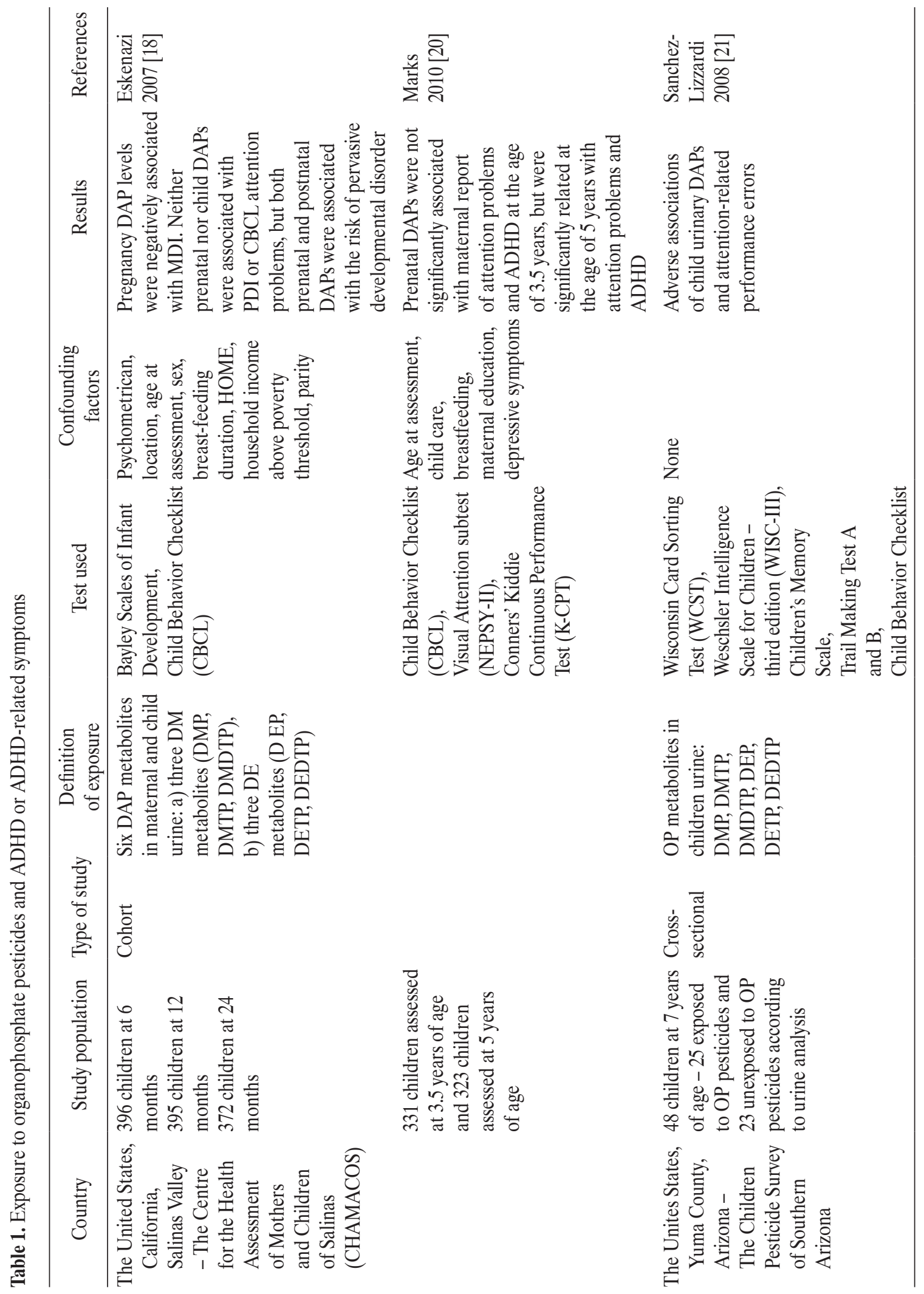




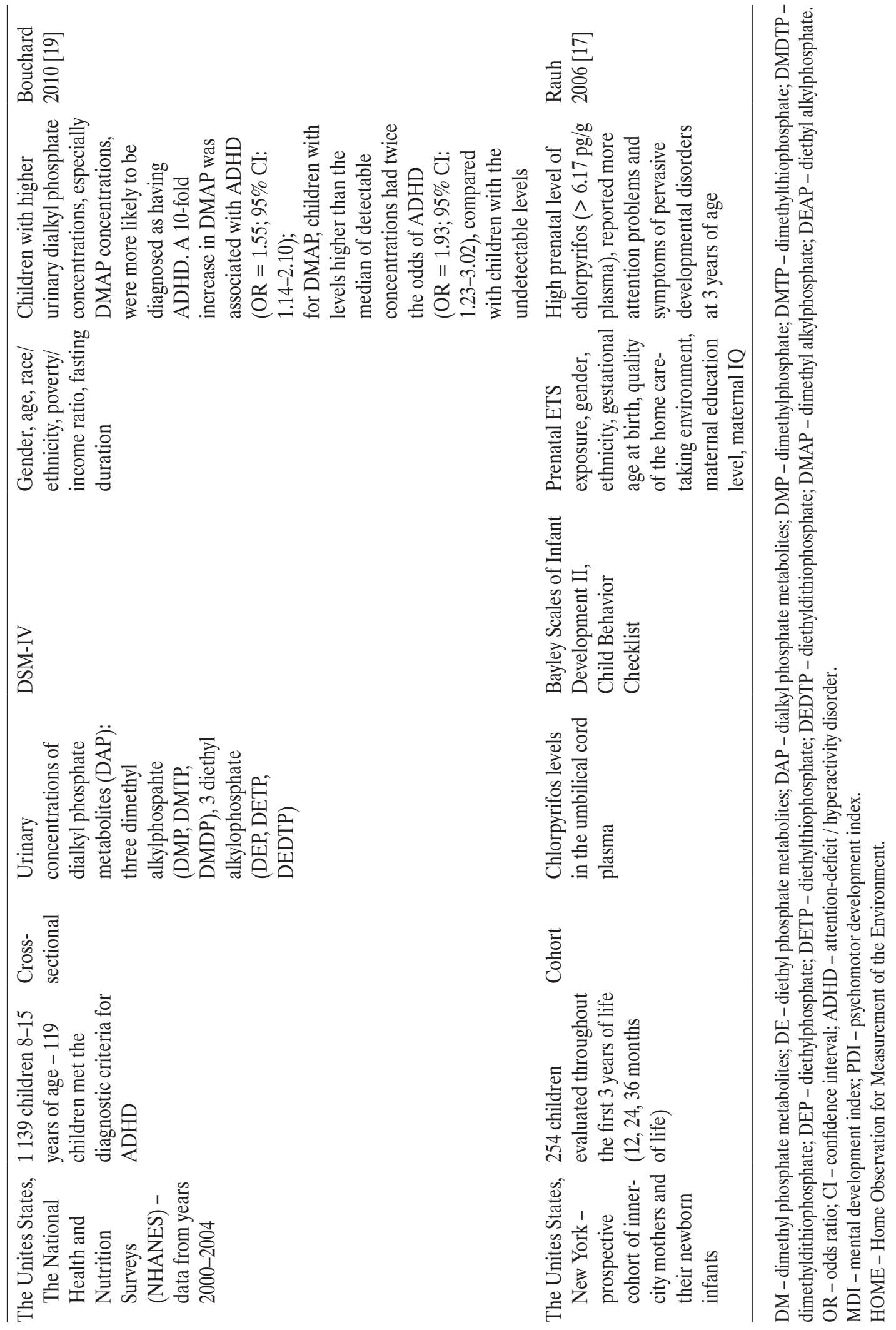


and psychomotor developments were also investigated in a cohort of farmworkers' children living in the Salinas Valley of California [18]. In the study, adverse associations of prenatal OP metabolites with mental development and pervasive development disorders at 24 months of age were observed. The same cohort study of children assessed at 3.5 and 5 years of age, showed exposures to dialkyl phosphates (DAPs) that were adversely associated with attention as assessed by maternal report, psychometrician observation, and direct assessment. These associations were slightly stronger at 5 years than at 3.5 years of age and were stronger in boys [20].

A recent cross-sectional study reported associations between child OP metabolite concentrations and ADHD in 8- to 15-year-olds characteristic (or typical) of the U.S. population [19]. Children with higher urinary dialkyl phosphate concentrations, especially dimethyl alkylphosphate (DMAP) concentrations, were more likely to be diagnosed with ADHD. For the DMAP metabolite, children with levels higher than the median of detectable concentrations had a twice higher chance of having ADHD, compared with children with the undetectable levels [19]. Adverse associations of child urinary DAPs and attentionrelated performance errors on the Wisconsin Card Sorting Test were reported in another cross-sectional study of Hispanic children living in an agricultural community [21]. The findings of the reviewed studies indicate that children's exposure to organophosphate pesticides may cause symptoms consistent with pervasive developmental disorder (PDD) [8,17] as well as attention deficit / hyperactivity disorder (ADHD) [17,19,20] or attention problems $[17,20,21]$.

\section{Organochlorine pesticides and polychlorinated biphenyls and ADHD or ADHD-related symptoms}

Organochlorines, including polychlorinated biphenyls (PCBs) and $p, p^{\prime}$-dichlorodiphenyl dichloroethylene ( $p, p^{\prime}$-DDE), are environmentally persistent contaminants that readily cross the placenta, posing a potential risk to the developing fetus. Associations of PCBs with ADHD-like behaviors have been observed in rodents and nonhuman primates [22-24]. There is a lack of sufficient knowledge of the biologic mechanism for the observed effect of PCBs and organocholrine pesticides on ADHD and attention in humans [25]. PCBs can disrupt dopaminergic functions, as reflected in alterations in dopamine levels in the cell culture and in the brains of laboratory animals [26,27]; this is one possible mechanism whereby PCBs may affect attention-related behaviors, since decreases in cellular dopamine have been correlated with attention disorders such as ADHD [28].

A number of epidemiological studies, which assess the neuropsychological consequences of exposure to PCBs, have been performed over the last 11 years [29-35] (Table 2). Only two studies have examined the association between cord PCBs and organochlorine pesticides ( $p, p^{\prime}$-DDE) and the risk of ADHD-related behaviors [25,36] (Table 2).

The Netherlands Cohort Study found associations between PCBs and a longer response time and more variations in the response time among 9-year-olds [29]. A study of children born to Lake Michigan fish consumers reported associations between prenatal PCB exposure and poorer concentration and verbal, pictorial and auditory working memory among 11-year-old children; the examined children also demonstrated greater impulsivity [30]. Investigators from the Oswego Newborn and Infant Development Project reported associations between prenatal PCBs and errors of commission (false - positive responses) on the Continuous Performance Test at 4.5, 8 , and 9.5 years of age, suggesting potential impairment of response inhibition [31,32]. The suggestion of potential impairment was supported by observing associations of PCBs with poorer performance on the Differential Reinforcement of Low Rates of Response test (in the same cohort study at the age of 9.5 years), which measures the 


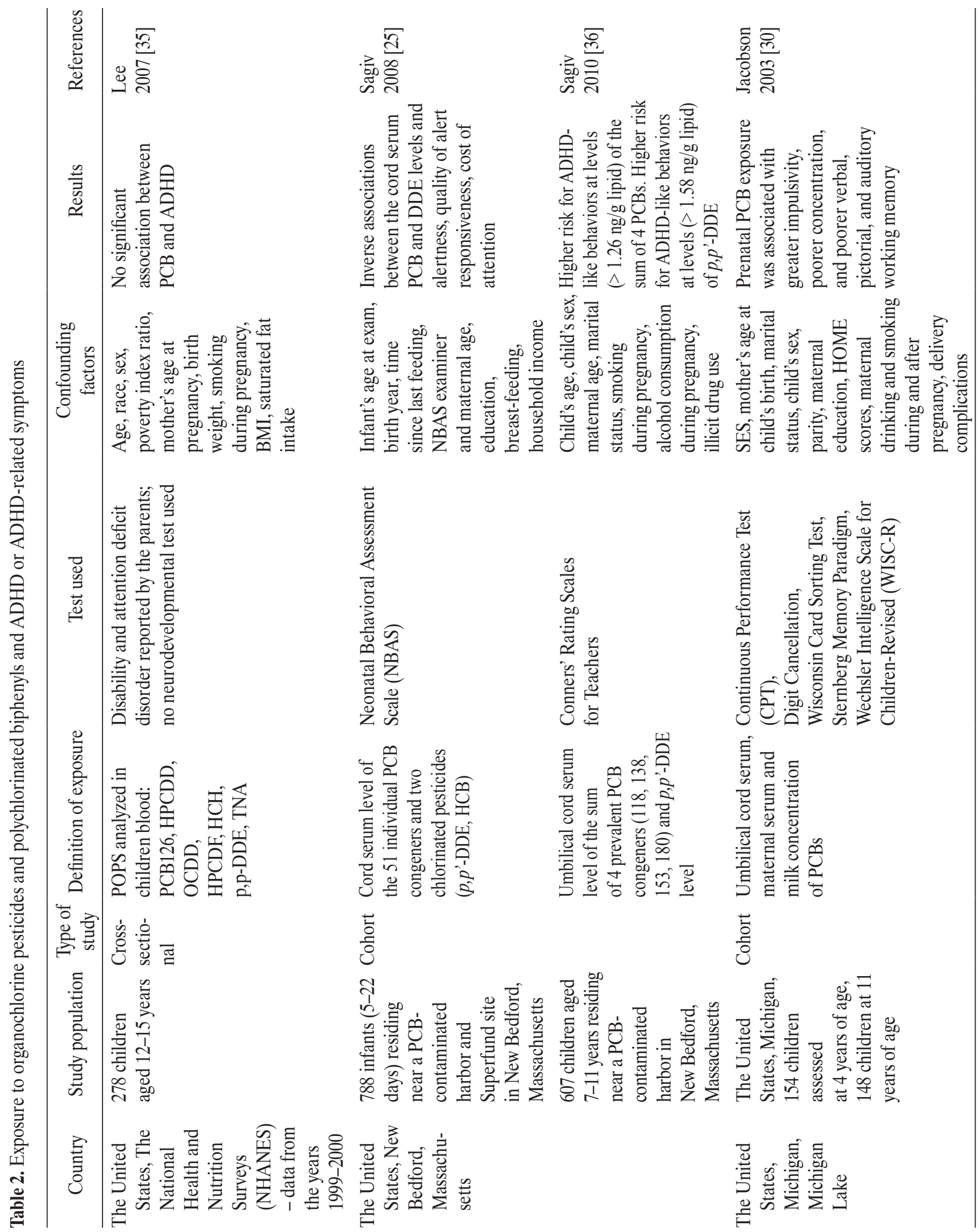




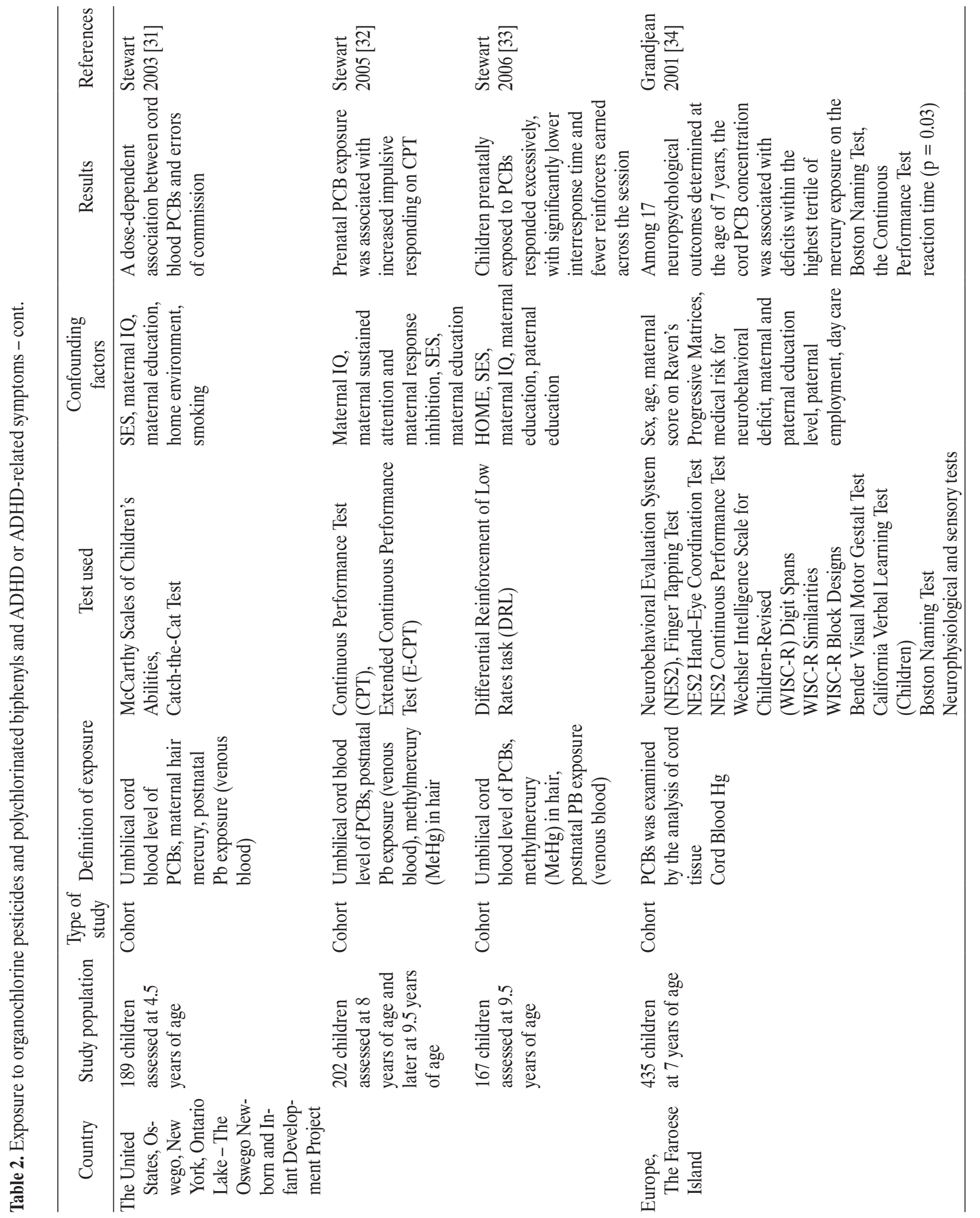




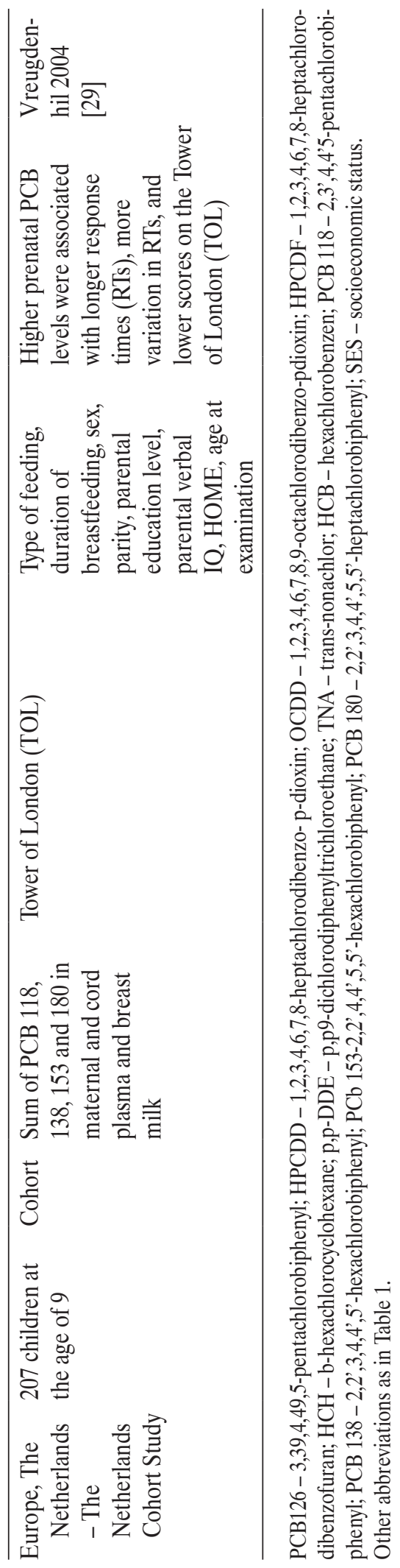

ability to withhold a rewarded response for a specific time delay [33]. The Faroe Islands study found associations between PCBs and attention measured by the Continuous Performance Test among children aged 7 years only in the context of high mercury exposure, suggesting a potential interaction between these contaminants [34].

Conversely, the study by Lee et al. [35] among 278 children aged 12-15 years did not find a link between the current child PCB levels and the attention deficit disorder.

To investigate an association between cord serum polychlorinated biphenyls (PCBs) and p,p'-DDE levels and measures of attention, Sagiv et al. [25] performed a study among 788 infants (5-22 days) born in the years 19931998 to mothers residing near a PCB-contaminated harbor and the Superfund site in New Bedford, Massachusetts. Consistent inverse associations between cord serum PCB and DDE levels and alertness, quality of alert responsiveness, cost of attention, and other potential attention-associated measures including self-quieting and motor maturity were observed [25]. The following study performed by Sagiv et al. [36] assessed the exposure to PCBs and DDE and ADHD among children aged 7-11 years from the same cohort study. The authors found higher risk for ADHD-like behaviors at the levels of $p, p^{\prime}$-DDE (> $1.58 \mathrm{ng} / \mathrm{g}$ lipid) and the levels of the sum of 4 PCBs (> $1.26 \mathrm{ng} / \mathrm{g}$ lipid).

The outcome of the presented studies has proven an association between exposure to organochlorine pesticides and PCBs and ADHD-like behaviors: alertness, quality of alert responsiveness, cost of attention, and other potential attention-associated measures including self-quieting and motor maturity $[25,36]$. In addition, studies found that exposure to PCBs can be linked with a longer, more variant response time, impairment of response inhibition [31-33], poorer concentration and verbal, pictorial and auditory working memory [30] and attention problems [34]. Only one study did not find an association between ADHD and ADHD-like behaviors and PCBs exposure [35]. 


\section{Mercury and ADHD or ADHD-related symptoms}

There are three basic forms of mercury: elemental, inorganic and organic. Deep-sea fish are commonly contaminated with organic methylmercury, which may be toxic to the brain when a moderate to large amount is ingested [37]. So far, there is scarce evidence on mercury-related ADHD behaviors in children, especially in areas with relatively low fish consumption. Mercury can adversely affect enzymes, the cellular membrane function, and neurotransmitter levels [38,39]. Mercury causes oxidative stress, lipid peroxidation, and mitochondrial dysfunction and disrupts synaptic transmission, microtubule formation, amino acid transport, and cellular migration in the developing brain [40], which can be associated with neurodevelopmental problems in children.

Studies, which investigated the possible link between exposure to mercury and ADHD or ADHD-related behaviors, were performed in China [37], Romania [41], South Korea [42], Faroe Islands [43,44], and in the Republic of Seychelles [45] (Table 3).

In a study performed in China, children with blood mercury level above $29 \mathrm{nmol} / \mathrm{l}$ had almost a 10-time higher risk of having ADHD after adjustment for confounding variables [37]. The ADHD behaviors were evaluated in the study performed in Faroe Islands among 14-year-old adolescents. Indicators of prenatal methylmercury exposure were significantly associated with deficits in finger tapping speed, reaction time on a continued performance task, and cued naming [43]. Additionally, among the same cohort of children in Faroe Islands, sustained attention was influenced by the prenatal methylmercury exposure [44]. The study performed by Myers et al. [45] in the Republic of Seychelles among 9-year-old children reported decreased performance in the grooved pegboard using the non-dominant hand in males, and improved scores in the hyperactivity index of the Conner's teacher rating scale associated with exposure to mercury (Table 3).
Conversely, Nicolescu et al. [41] did not find a significant association between concurrent mercury levels and ADHD symptom scores in a cross-sectional study of Romanian children. The findings are in agreement with the study of bigger sample sizes that did not find a significant relationship between mercury exposure and ADHDrelated outcomes [42].

The results of the studies presented above are inconsistent. Ha [42] and Nicolescu [42] did not find a significant relationship between mercury exposure and ADHD, whereas Cheuk [37] found higher risk of ADHD among children with exposure to mercury.

Some studies suggest a link between exposure to mercury and ADHD behaviors: increased hyperactivity scores [45], sustained attention [44] and deficits in finger tapping speed and reaction time [43], but as the number of studies is rather limited, the observations need to be confirmed in other epidemiological studies.

\section{Lead and ADHD or ADHD-related symptoms}

Lead is one of well-established environmental toxicants, and its adverse effects, particularly in children, continue to be a major public health issue worldwide. It is well known that lead can cause cognitive impairment and correlate with decreased IQ scores and impaired attention. The World Health Organization and U.S. Centers for Disease Control and Prevention recommended that child blood lead levels not exceed $10 \mu \mathrm{g} / \mathrm{dl}$ [46]. Furthermore, recent studies have shown that cognitive deficits and behavioral problems in children still exist, even with blood lead level $<10 \mu \mathrm{g} / \mathrm{dl}$, and that no threshold below which lead does not cause neurodevelopmental toxicity can be defended $[46,47]$.

Lead is a potent developmental neurotoxin that can affect multiple neurochemical pathways and interfere with blood-brain capillary integrity, synaptogenesis, myelination, and catecholamine metabolism in the central nervous system [48]. These multiple potent effects occur in 


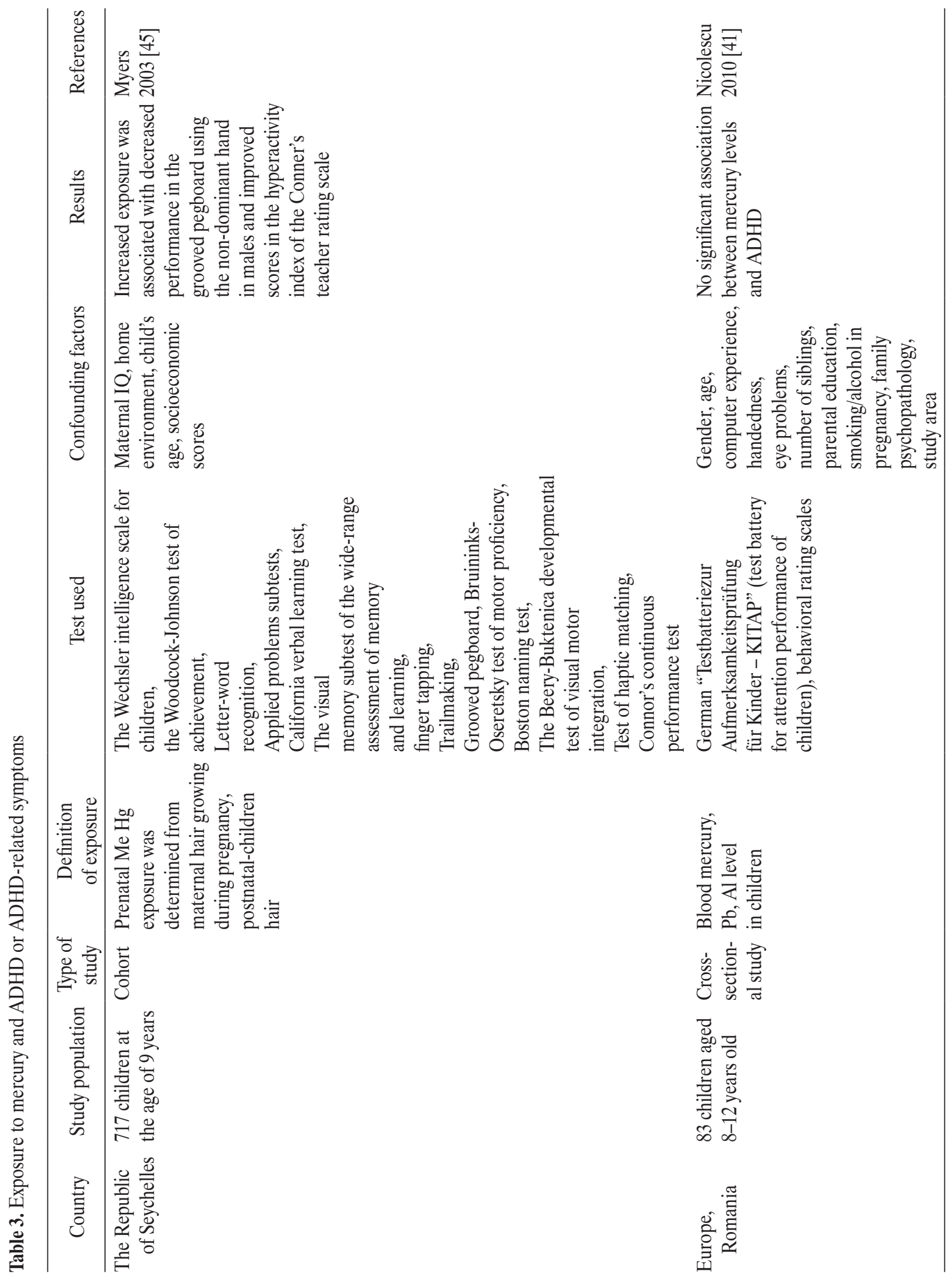




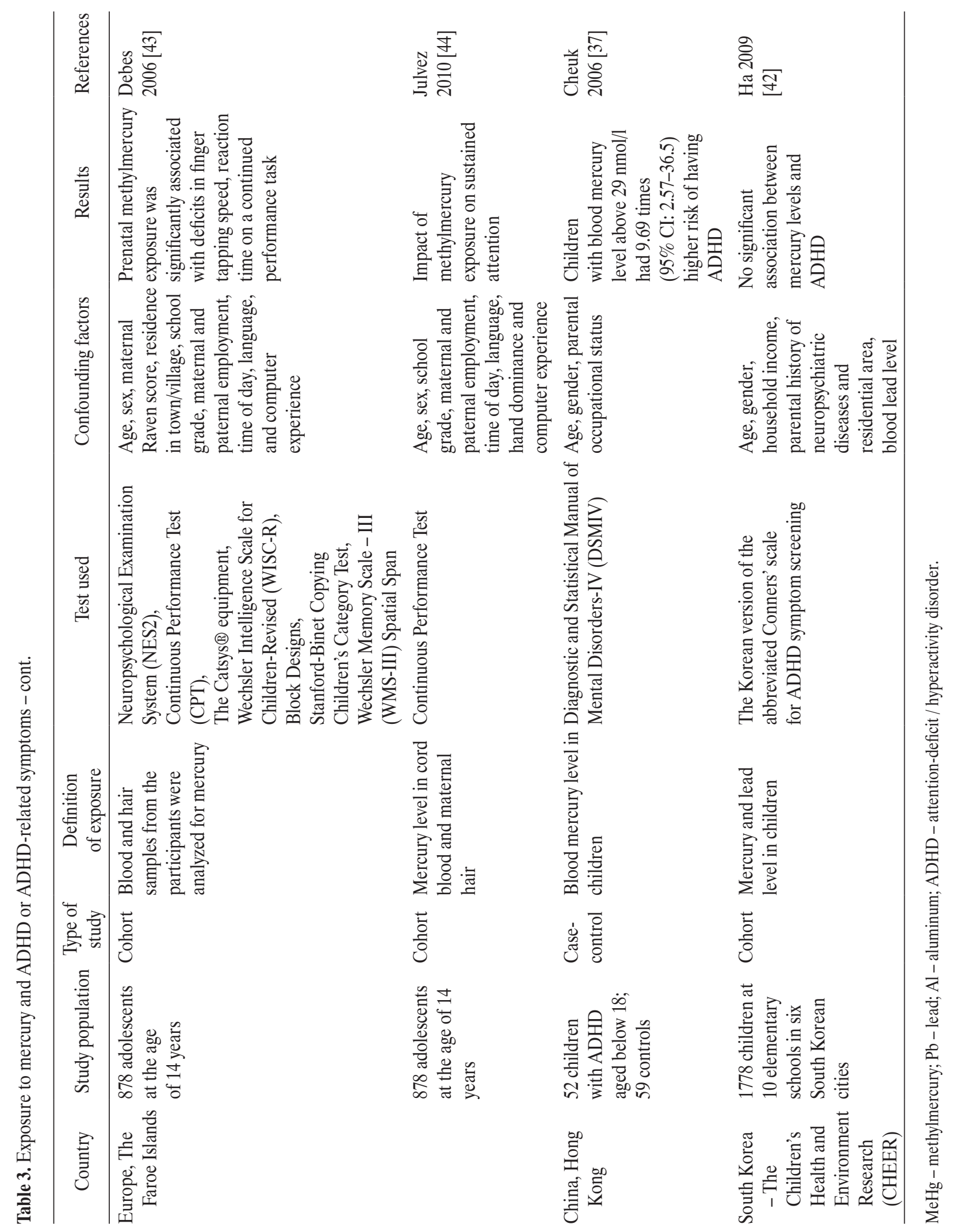


the dopaminergic neurons of the striatal-frontal circuitry. Among the psychological functions related to these circuits, there are response suppression and response variability [49,50].

Eleven studies evaluating the impact of lead exposure on ADHD or ADHD-related symptoms have been identified since 2000 (Table 4).

In the published studies, the relationship with $\mathrm{ADHD}$ was reported even at the blood lead level well below the CDC's $10 \mu \mathrm{g} / \mathrm{dl}$ action level. For instance, the analysis from the National Health and Nutrition Examination Survey on 4704 children aged 4-15 years indicated the prevalence of parent-reported ADHD diagnosis or treatment four times higher among children with the blood lead level $>2.0 \mu \mathrm{g} / \mathrm{dl}$, compared with those with the blood lead level $<0.8 \mu \mathrm{g} / \mathrm{dl}(\mathrm{OR}=4.1 ; 95 \%$ CI: 1.2-10.0) [6]. The later analysis conducted as part of the same survey (on 2588 children at 8-15 years of age) indicated that children who were exposed to prenatal tobacco and lead had greater risk of ADHD than it would be expected if the independent risk was multiplied $(\mathrm{OR}=8.1$; $95 \% \mathrm{CI}$ : 3.5-18.7; tobacco - lead exposure interaction $\mathrm{p}<0.001$ ) [51].

Additionally, studies conducted in South Korea [42], China [52], India [53], and the US [54,55] also suggest a link between the blood lead level and the diagnosis or symptoms of ADHD. Four studies investigating the link between lead exposure and ADHD and/or ADHD-related symptoms were published in 2010 [41,56-58]. The strength of those studies lies in the adjustments for a number of potential confounders, but their weakness is that each of them depended on a single concurrent blood lead level, making it difficult to disentangle the effects of prenatal or earlier childhood levels from the current levels. The findings of the studies are consistent with earlier literature reports demonstrating increased risk of ADHD or ADHDrelated symptoms in case of lead exposure.

To sum up, the presented studies indicated that low lead exposure levels (with mean levels below the CDC action level of $10 \mu \mathrm{g} / \mathrm{dl}$ ) are associated with the increased risk of ADHD.

\section{Manganese and ADHD or ADHD-related symptoms}

Manganese (Mn) is a naturally occurring element that constitutes approximately $0.1 \%$ of the Earth's crust, and low levels of Mn in water, food, and air are ubiquitous [59]. Several authors have hypothesized that excessive amount of Mn could have detrimental effects on children's behavior patterns [59].

High exposure to airborne $\mathrm{Mn}$ has been associated with neurotoxic effects, with the worst cases displaying the extrapyramidal syndrome (manganism), characterized by gait dysfunction with a propensity to fall backward, postural instability, bradykinesia, rigidity, micrographia, masked facies, speech disturbances, and muscle tremors [60]. Lower levels of exposure may produce neurobehavioral deficits involving motor and cognitive functions, as well as psychological perturbations [61,62].

So far, only two studies have been carried out to examine the association between exposure to $\mathrm{Mn}$ and $\mathrm{ADHD}$ or ADHD-like symptoms and both suggested the presence of such relationship [63,59] (Table 5).

A case-control study by Farias et al. [63] found that children with ADHD of both the inattentive and ADHDcombined types had higher serum manganese levels compared with the controls, however the study did not control for potential confounders. Also, the study performed in Quebec reported a significant association between higher manganese levels in hair and drinking water and hyperactive behaviors in school children after controlling for sex, age and income [59].

\section{Summary of the study results}

$\mathrm{ADHD}$ is a complex disorder with great heterogenicity in the behavioral symptoms and affected brain functions and structures [2]. Although much research has been done on the impact of genetic, environmental, industrial and 


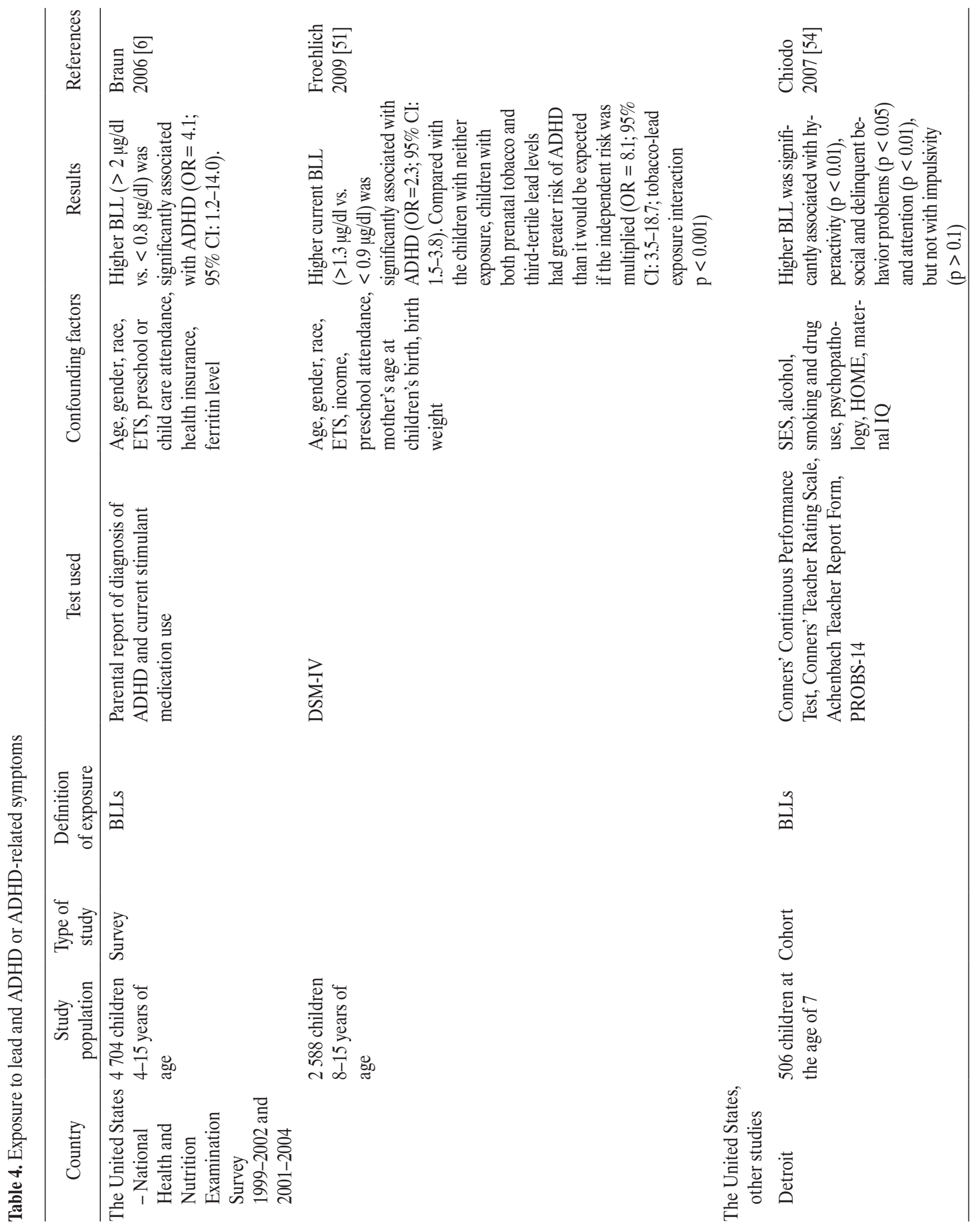




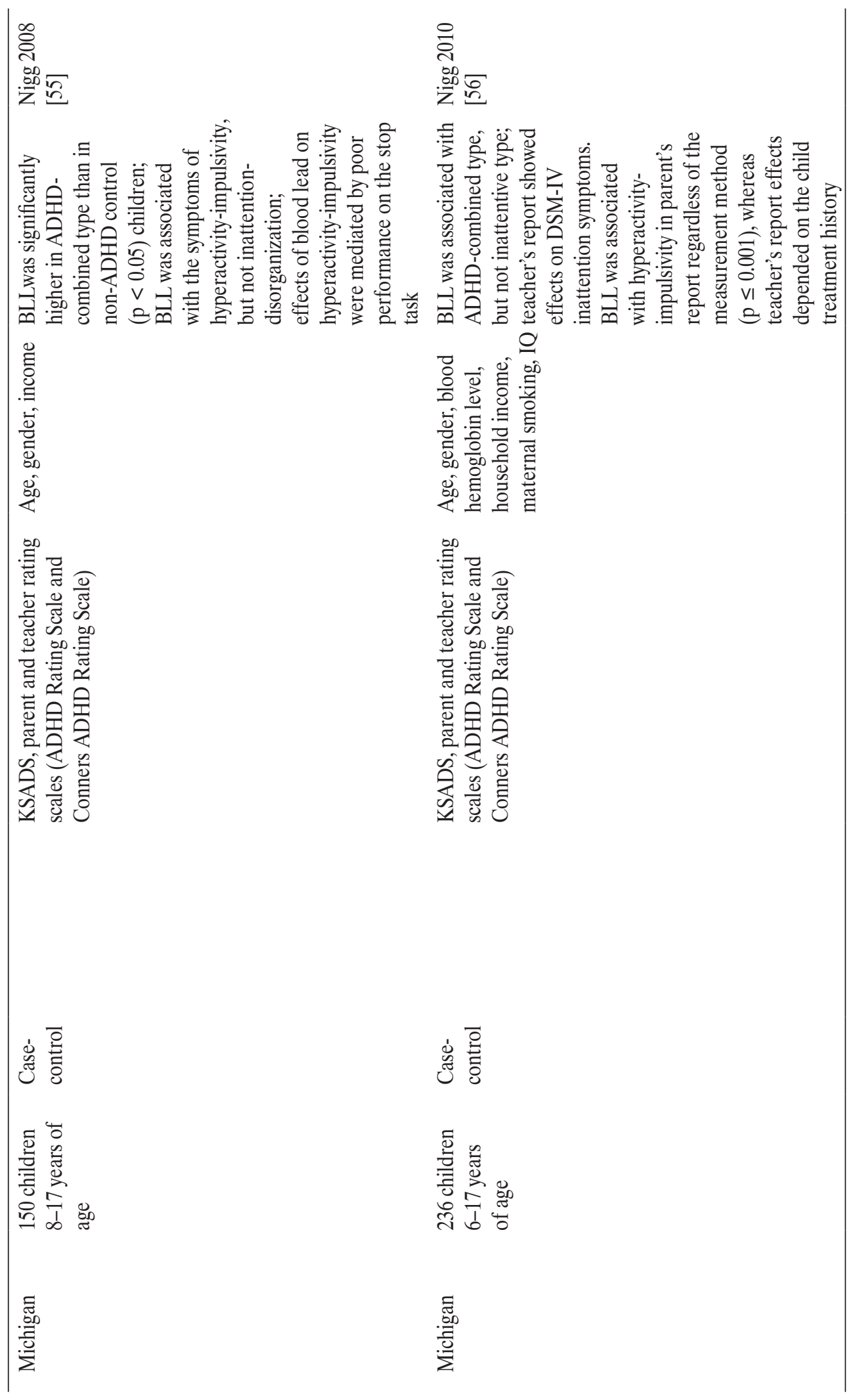




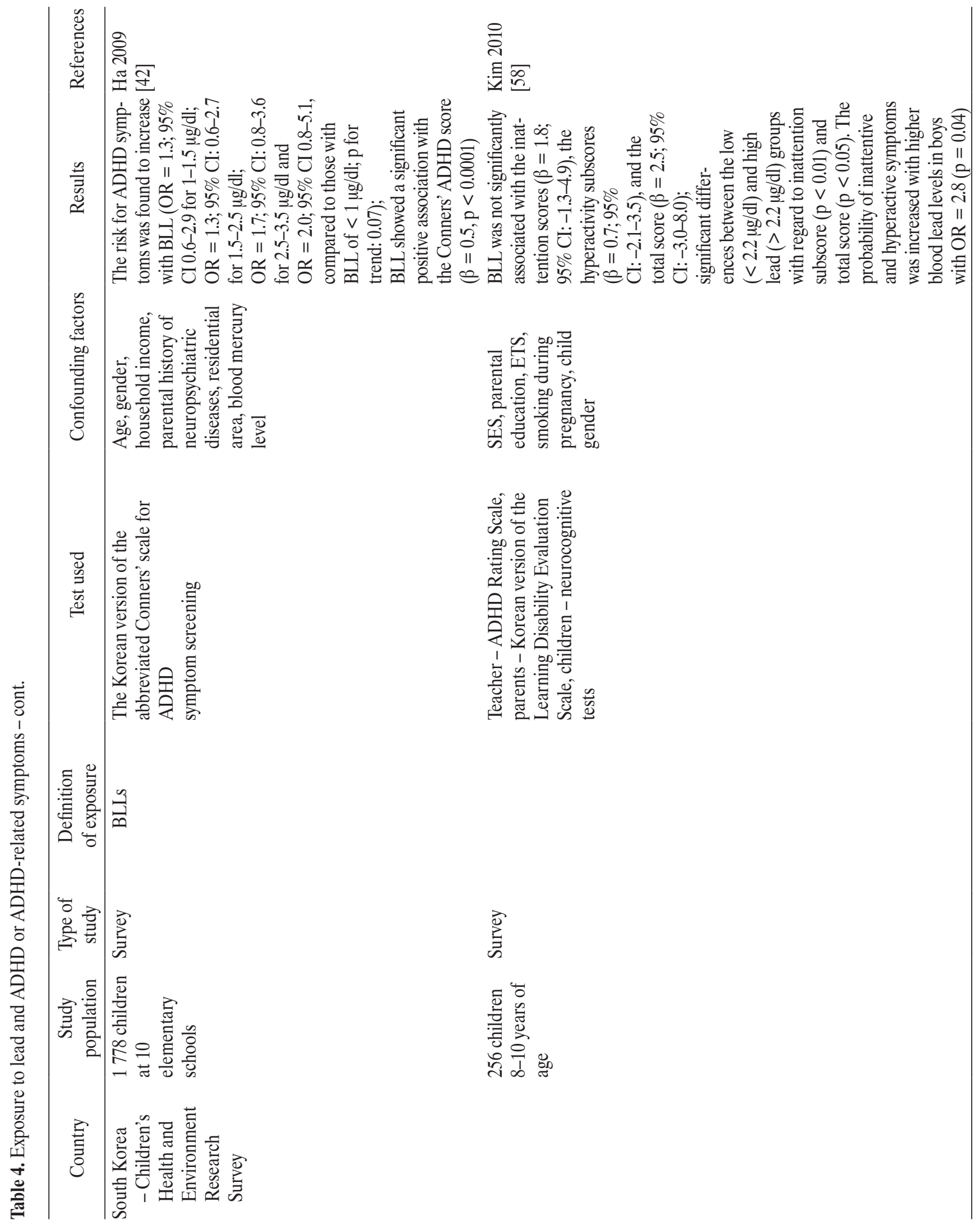




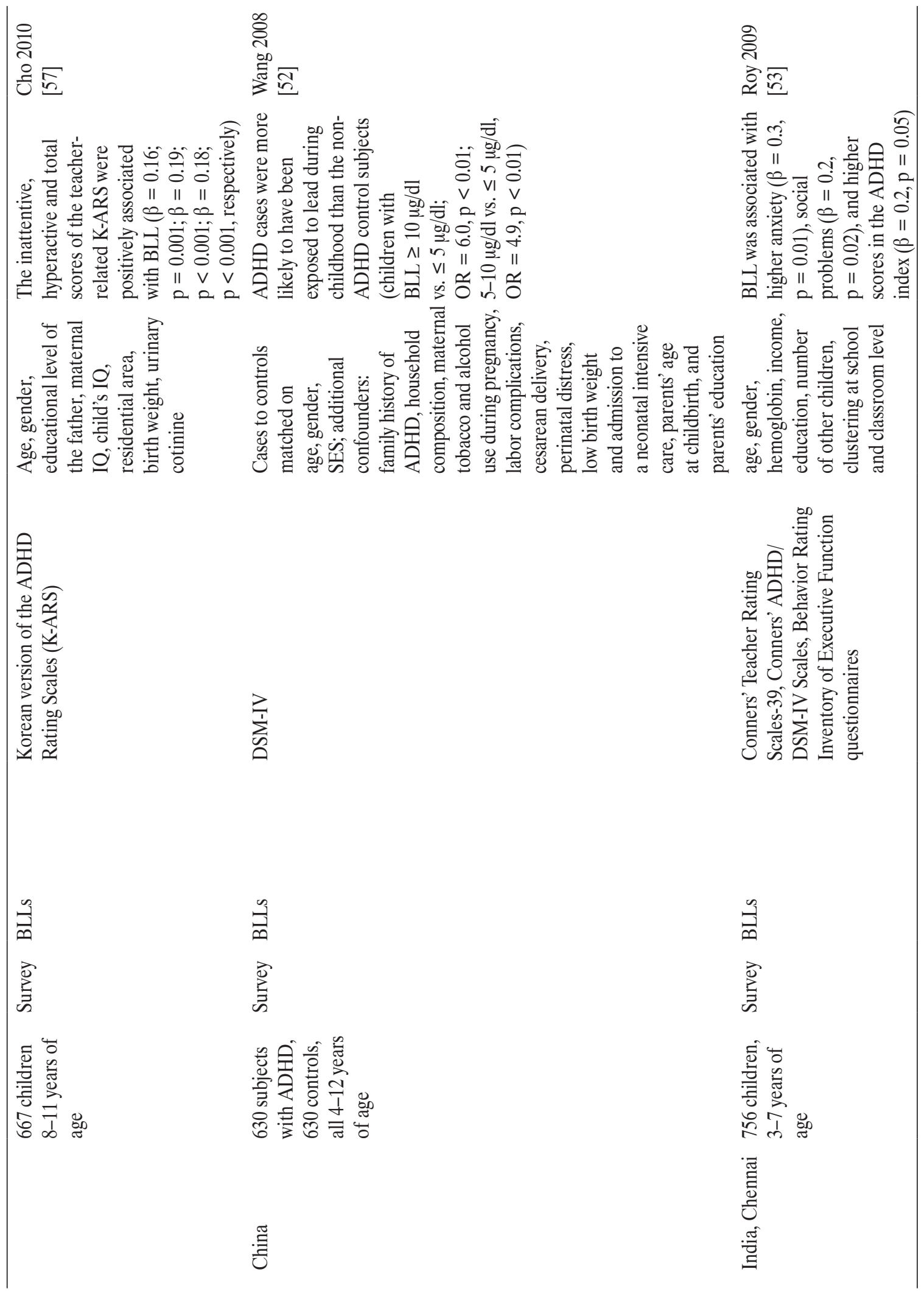




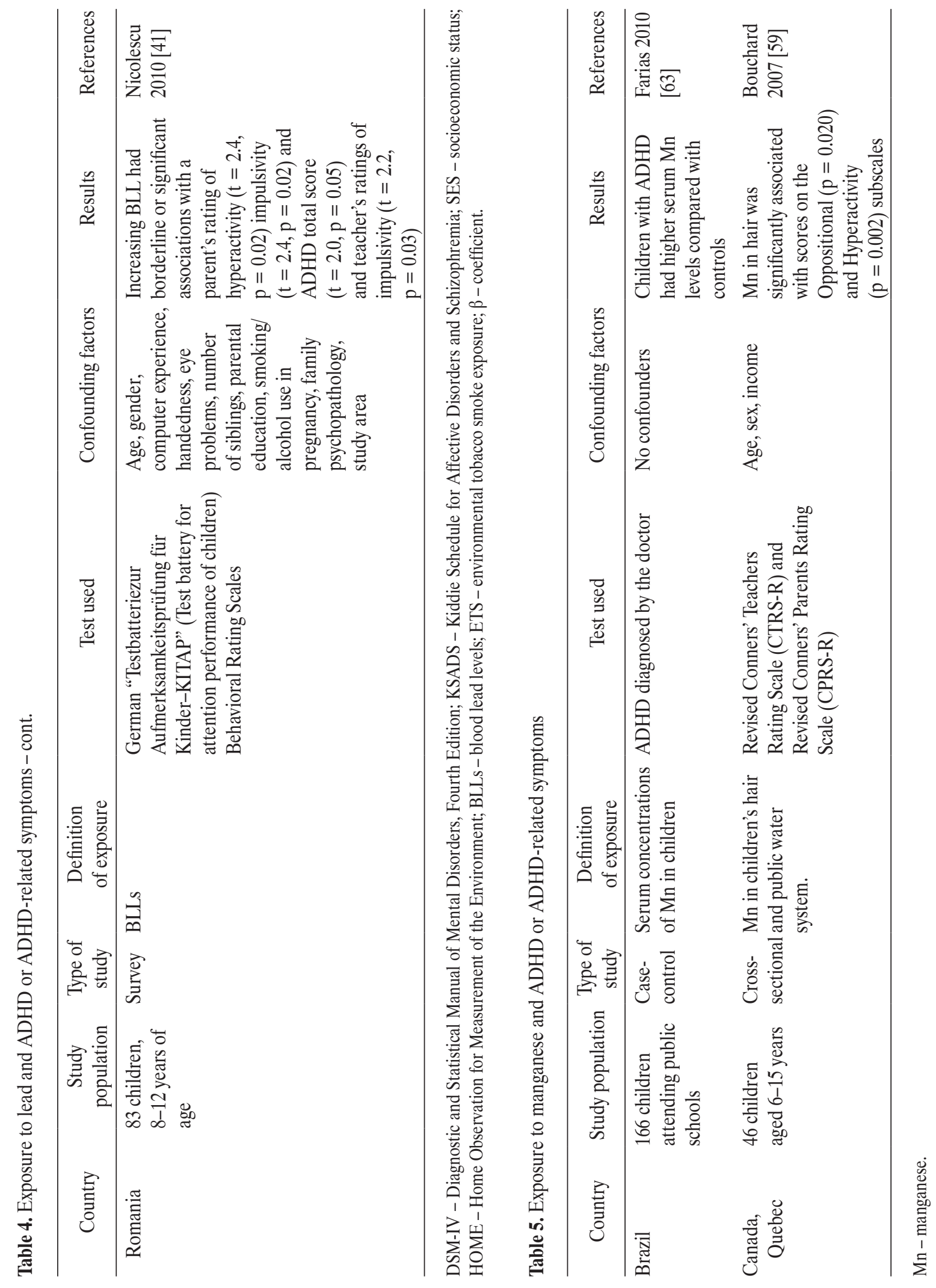


lifestyle factors on $\mathrm{ADHD}$, we are still far from understanding its etiology. Given the inability to explain ADHD on a solely genetic basis, interest in the contribution of environmental/lifestyle factors, including exposure to industrial chemicals, has been intensified.

Table 6 presents the summary of the results of the studies analyzing the association between the exposure to industrial chemicals and ADHD or ADHD-like symptoms. Most of the presented studies are focused on pesticides, PCB and lead, whereas the impact of mercury and manganese has been investigated less frequently. The findings of the reviewed studies indicate that children's exposure to organophosphate pesticides may cause symptoms consistent with PDD as well as with ADHD or attention problems. Exposures to organochlorine pesticides and PCBs were associated with ADHD-like behaviors: alertness, quality of alert responsiveness, cost of attention, and other potential attention-associated measures including self-quieting and motor maturity. Lead is probably the best studied toxic element. The studies in this field provided evidence that low levels of lead in the blood (well below the CDC's $10 \mu \mathrm{g} / \mathrm{dl}$ action level) were associated with ADHD or ADHD-related symptoms and no threshold below which lead does not cause neurodevelopmental toxicity can be defended. Information from the studies on the association between mercury exposure, especially in the postnatal period, and neurotoxicity is limited. Therefore, the association between exposure to this heavy metal and ADHD requires further confirmation in future studies. Two studies indicated that there is an association between exposure to manganese and ADHD or ADHDrelated symptoms. As there are no other studies on this topic, such exposure and its impact on child neurodevelopment need to be further investigated.

In the presented studies, the assessment of the exposure to industrial chemicals is based on the measurements of biomarkers and not questionnaire data, which decreases the risk of exposure misclassification. A single measurement during pregnancy, delivery or childhood period may not be sufficient to judge when the window of exposure occurred.

In some of the studies included in the review, ADHD diagnosis was made through an extensive clinical evaluation based on the DSM-IV diagnostic instrument. Others focused on specific symptoms - such as attention problems, impulsivity or hyperactivity.

The possible co-exposures to other relevant, but not measured, environmental/lifestyle contaminants and confounding factors are important issues to be considered in order to avoid under- or over-estimation of the association between the exposure and outcome of interest. For example, the analysis performed by Froehlich et al. [51] indicated that, compared with children with neither exposure, children with both exposures (prenatal tobacco and lead) had a greater risk of ADHD than would be expected if the independent risks were multiplied (tobacco-lead exposure interaction $\mathrm{p}<0.001$ ). Particularly important confounders include, parental intelligence, parental criminality and mental disorders to account for genetic background. For practical reasons, in some studies, maternal education/IQ and psychopathology are taken as proxy for the parental one. In addition to the heritability factors, the reported environmental risk factors for ADHD include: pregnancy and delivery complications, low birth weight, maternal smoking, and illicit drug and alcohol intake during pregnancy [42]. Furthermore, the quality of home environment (e.g. low social class, low income, large family size, family dysfunction and single parent families) has been reported to be a risk factor for psychopathology and behavioral problems in children. The quality of home environment is mostly measured by means of the Home Observation for Measurement of the Environment (HOME) Scale. It covers the emotional and verbal responsibility of the mother, acceptance of the child's behavior, organization of the home environment, availability of toys, parental involvement and variability of daily experience. 
Table 6. Summary of chemical exposure impact on ADHD or ADHD-related symptoms based on the reviewed literature

\begin{tabular}{|c|c|c|c|c|c|c|}
\hline $\begin{array}{l}\text { ADHD or ADHD- } \\
\text { related symptoms }\end{array}$ & OP pesticides & PCB & $\begin{array}{c}\text { Organochorine } \\
\text { pesticides and PCB }\end{array}$ & $\mathrm{Hg}$ & $\mathrm{Pb}$ & $\mathrm{Mn}$ \\
\hline ADHD & $\begin{array}{l}\text { + Marks } 2010 \\
\text { [20], } \\
\text { Bouchard } 2010 \\
{[19],} \\
\text { Rauh } 2006 \text { [17] }\end{array}$ & $\begin{array}{l}\text { - Lee } 2006 \\
{[35]}\end{array}$ & + Sagiv $2010[36]$ & $\begin{array}{l}\text { + Cheuk } 2006 \\
\text { [37] } \\
\text {-Nicolescu } 2010 \\
{[41],} \\
\text { Ha 2009 [42] }\end{array}$ & $\begin{array}{l}\text { + Braun } 2006 \text { [6], } \\
\text { Wang } 2008 \text { [52], } \\
\text { Froehlich 2009 [51], } \\
\text { Nigg 2008 [55], 2010 } \\
\text { [56], } \\
\text { Ha } 2009 \text { [42], } \\
\text { Roy } 2009 \text { [53] }\end{array}$ & $\begin{array}{l}\text { + Farias } \\
2010[63]\end{array}$ \\
\hline Attention problems & $\begin{array}{l}\text { + Marks } 2010 \\
\text { [20], Sanchez- } \\
\text { Lizzardi } 2008 \text { [21], } \\
\text { Rauh } 2006 \text { [17] }\end{array}$ & $\begin{array}{l}\text { + Grandjean } \\
2001[34]\end{array}$ & + Sagiv 2008 [25] & + Juvlez 2010 [44] & $\begin{array}{l}\text { + Chiodo } 2007 \text { [54], } \\
\text { Cho } 2010[57], \\
\text { Kim } 2010 \text { [58] } \\
\text { - Nigg } 2008[55]\end{array}$ & \\
\hline Impulsivity & & $\begin{array}{l}\text { + Stewart } \\
2003[31], \\
2005[32], 2006 \\
{[33]}\end{array}$ & & & $\begin{array}{l}\text { + Nigg } 2008 \text { [55], } \\
\text { Nicolescu } 2010 \text { [41] } \\
\text {-Chiodo } 2007 \text { [54] }\end{array}$ & \\
\hline Hyperactivity & & & & + Myers 2003 [45] & $\begin{array}{l}\text { + Chiodo } 2007 \text { [54], } \\
\text { Nigg 2008 [55], } \\
\text { Cho 2010 [57], } \\
\text { Nicolescu 2010 [41] }\end{array}$ & $\begin{array}{l}\text { + Bouchard } \\
2007[59]\end{array}$ \\
\hline $\begin{array}{l}\text { Anxious and } \\
\text { depressed behavior }\end{array}$ & & & & & + Roy 2009 [53] & \\
\hline Delinquent behavior & & & & & + Chiodo 2007 [54] & \\
\hline $\begin{array}{l}\text { Pervasive develop- } \\
\text { mental disorders }\end{array}$ & $\begin{array}{l}\text { + Eskanzai } 2007 \\
{[18],} \\
\text { Rauh } 2006[17]\end{array}$ & & & & & \\
\hline Quality of alertness & & & + Sagiv 2008 [25] & & & \\
\hline $\begin{array}{l}\text { Longer response } \\
\text { time; more varia- } \\
\text { tion in response } \\
\text { time; impairment } \\
\text { of response inhibi- } \\
\text { tion; impulsive } \\
\text { responding }\end{array}$ & & $\begin{array}{l}\text { + Verugdenhil } \\
2004[29] \\
\text { Stewart 2003, } \\
2005,2006 \\
{[31-33]}\end{array}$ & & & & \\
\hline $\begin{array}{l}\text { Worse working mem- } \\
\text { ory and concentra- } \\
\text { tion, orientation }\end{array}$ & & $\begin{array}{l}\text { + Jacobson } \\
2003[30]\end{array}$ & & & & \\
\hline Deficits reaction time & & & & + Debes 2006 [43] & & \\
\hline
\end{tabular}

"+" - statistically significant association between the exposure to environmental toxicants and ADHD or ADHD-related symptoms.

“-" - no statistically significant association between the exposure to environmental toxicants and ADHD or ADHD-related symptoms. 
Finally, there is relatively extensive body of literature reporting the effects of neurodevelopmental exposure to pesticides, PCBs and lead. The impact of mercury and manganese on ADHD and ADHD-related symptoms needs to be further investigated. Future studies should use a prospective design, with multiple biological samples collected over time for the better assessment of exposure and its critical windows. Additionally, the inclusion of potential confounding factors and co-exposures is crucial for reliable assessment of the impact of exposure on ADHD.

\section{REFERENCES}

1. Polanczyk G, Lima MS, Horta BL, Biederman J, Rohde LA. The worldwide prevalence of ADHD: A systematic review and metaregression analysis. Am J Psychiatry 2007;164:942-8.

2. Aguiar A, Eubig PA, Schantz SL. Attention deficit/hyperactivity disorder: A focused overview for children's environmental health researchers. Environ Health Perspect 2010;118(12):1646-53.

3. American Psychiatric Association. Diagnostic and Statistical Manual of Mental Diseases (DSM-IV). 4th ed. Washington, DC: American Psychiatric Publishing; 1994.

4. World Health Organization. The ICD-10 Classification on Mental and Behavioral Disorders: Diagnostic Criteria for Research. Geneva: World Health Organization; 1993.

5. Smith AK, Mick S, Faraone SV. Advances in genetic studies of attention-deficit/hyperactivity disorder. Curr Psychiatry Rep 2009;11(2):143-148.

6. Braun JM, Kahn RS, Froehlich T, Auinger P, Lanphear BP. Exposures to environmental toxicants and attention deficit hyperactivity disorder in U.S. children. Environ Health Perspect 2006;114(12):1904-9.

7. Jokanovic M. Medical treatment of acute poisoning with organophosphorus and carbamate pesticides. Toxicol Lett 2009;190(2):107-15.

8. Timofeeva OA, Sanders D, Seemann K, Yang L, Hermanson D, Regenbogen S, et al. Persistent behavioral alterations in rats neonatally exposed to low doses of the organophosphate pesticide, parathion. Brain Res Bull 2008;77(6):404-11.

9. Furlong CE, Holland N, Richter RJ, Bradman A, Ho A, Eskenazi B. PON1 status of farmworker mothers and children as a predictor of organophosphate sensitivity. Pharmacogenet Genomics 2006;16(3):183-90.

10. Holland N, Furlong C, Bastaki M, Richter R, Bradman A, Huen K, et al. Paraoxonase polymorphisms, haplotypes, and enzyme activity in Latino mothers and newborns. Environ Health Perspect 2006;114:985-91.

11. Sultatos LG. Mammalian toxicology of organophosphorus pesticides. J Toxicol Environ Health 1994;43(3):271-89.

12. Coccini T, Crevani A, Rossi G, Assandri F, Balottin U, Nardo RD, et al. Reduced platelet monoamine oxidase type B activity and lymphocyte muscarinic receptor binding in unmedicated children with attention deficit hyperactivity disorder. Biomarkers 2009;14(7):513-22. DOI: 10.3109/13547500903144436.

13. Verma SK, Kumar V, Gill KD. An acetylcholinesterase-independent mechanism for neurobehavioral impairments after chronic low level exposure to dichlorvos in rats. Pharmacol Biochem Behav 2009;92(1):173-81.

14. Slotkin TA, Seidler FJ. Comparative developmental neurotoxicity of organophosphates in vivo: transcriptional responses of pathways for brain cell development, cell signaling, cytotoxicity and neurotransmitter systems. Brain Res Bull 2007;72 (4-6):232-74.

15. Heath CJ, Picciotto MR. Nicotine-induced plasticity during development: modulation of the cholinergic system and longterm consequences for circuits involved in attention and sensory processing. Neuropharmacology 2009;56(Suppl 1):254-262.

16. Slotkin TA. Cholinergic systems in brain development and disruption by neurotoxicants: nicotine, environmental tobacco smoke, organophosphates. Toxicol Appl Pharmacol 2004;198(2):132-51.

17. Rauh VA, Garfinkel R, Perera FP, Andrews HF, Hoepner L, Barr DB, et al. Impact of prenatal chlorpyrifos exposure on neurodevelopment in the first 3 years of life among inner-city children. Pediatrics 2006;118(6):1845-59. 
18. Eskenazi B, Marks AR, Bradman A, Harley K, Barr DB, Johnson C. Organophosphate pesticide exposure and neurodevelopment in young Mexican-American children. Environ Health Perspect 2007;115(5):792-8.

19. Bouchard MF, Bellinger DC, Wright RO, Weisskopf MG. Attention-deficit/hyperactivity disorder and urinary metabolites of organophosphate pesticides. Pediatrics 2010;125:1270. DOI 10.1542/peds.2009-3058

20. Marks AR, Harley K, Bradman A, Kogut K, Barr DB, Johnson $\mathrm{C}$, et al. Organophophate pesticide exposure and attention in young Mexican-American children: the CHAMACOS study. Environ Health Perspect 2010;118(12):1768-74.

21. Sánchez Lizard P, O'Rourke MK, Morris RJ. The effects of organophosphate pesticide exposure on hispanic children's cognitive and behavioral functioning. J Pediatr Psychol 2008;33(1):91-101.

22. Berger DF, Lombardo JP, Jeffers PM, Hunt AE, Bush B, Casey A, et al. Hyperactivity and impulsiveness in rats fed diets supplemented with either Aroclor 1248 or PCB - contaminated St. Lawrence river fish. Behav Brain Res 2001;126(1-2):1-11.

23. Holene E, Nafstad I, Skaare JU, Sagvolden T. Behavioural hyperactivity in rats following postnatal exposure to subtoxic doses of polychlorinated biphenyl congeners 153 and 126. Behav Brain Res 1998;94(1):213-24.

24. Rice DC. Parallels between attention deficit hyperactivity disorder and behavioral deficits produced by neurotoxic exposure in monkeys. Environ Health Perspect 2000;108(Suppl 3):405-8.

25. Sagiv SK, Nugent JK, Brazelton TB, Choi AL, Tolbert PE, Altshul LM, et al. Prenatal organochlorine exposure and measures of behavior in infancy using the Neonatal Behavioral Assessment Scale (NBAS). Environ Health Perspect 2008;116(5):666-73.

26. Seegal RF, Brosch KO, Okoniewski RJ. Effects of in utero and lactational exposure of the laboratory rat to 2,4,2,4'and 3,4,3', 4'-tetrachlorobiphenyl on dopamine function. Toxicol Appl Pharmacol 1997;146(1):95-103.

27. Seegal RF, Okoniewski RJ, Brosch KO, Bemis JC. Polychlorinated biphenyls alter extraneuronal but not tissue dopamine concentrations in adult rat striatum: An in vivo microdialysis study. Environ Health Perspect 2002;110:1113-7.

28. Faraone SV, Biederman J. Neurobiology of attention-deficit hyperactivity disorder. Biol Psychiatry 1998;44(10):951-58.

29. Vreugdenhil HJI, Mulder PGH, Emmen HH, Weisglas-Kuperus N. Effects of perinatal exposure to PCBs on neuropsychological functions in the Rotterdam cohort at 9 years of age. Neuropsychology 2004;18:185-93.

30. Jacobson JL, Jacobson SW. Prenatal exposure to polychlorinated biphenyls and attention at school age. J Pediatr 2003;143:700-88.

31. Stewart P, Fitzgerald S, Reihman J, Gump B, Lonky E, Darvill T, et al. Prenatal PCB exposure, the corpus callosum, and response inhibition. Environ Health Perspect 2003;111(13):1670-77.

32. Stewart P, Reihman J, Gump B, Lonky E, Darvill T, Pagano J. Response inhibition at 8 and $91 / 2$ years of age in children prenatally exposed to PCBs. Neurotoxicol Teratol 2005;27(6):771-80.

33. Stewart PW, Sargent DM, Reihman J, Gump BB, Lonky E, Darvill T, et al. Response inhibition during Differential Reinforcement of Low Rates (DRL) schedules may be sensitive to low-level polychlorinated biphenyl, methylmercury, and lead exposure in children. Environ Health Perspect 2006;114(12):1923-29.

34. Grandjean P, Weihe P, Burse VW, Needham LL, Storr-Hansen E, Heinzow B, et al. Neurobehavioral deficits associated with PCB in 7-year-old children prenatally exposed to seafood neurotoxicants. Neurotoxicol Teratol 2001.23:305-17.

35. Lee DH., Jacobs DR., Porta M. Association of serum concentrations of persistent organic pollutants with the prevalence of learning disability and attention deficit disorder. J Epidemiol Community Health 2007;61:591-96.

36. Sagiv SK, Thurston SW, Bellinger DC, Tolbert PE, Altshul LM, Korrick SA. Prenatal Organochlorine Exposure and Behaviors Associated With Attention Deficit Hyperactivity Disorder in School-Aged Children. Am J Epidemiol 2010;171(5):593-601. 
37. Cheuk DKL, Wong V. Attention-deficit hyperactivity disorder and blood mercury level: A case-control study in Chinese children. Neuropediatrics 2006; 37:234-40.

38. Atchison WD, Hare MF. Mechanisms of methylmercury-induced neurotoxicity. FASEB J 1994;8(9):622-9.

39. Sager PR. Selectivity of methylmercury effects on cytoskeleton and mitotic progression in cultured cells. Toxicol Appl Pharm 1988; 94(3):473-86.

40. Sager PR, Matheson DW. Mechanisms of neurotoxicity related to selective disruption of microtubules and intermediate filaments. Toxicology 1988;49(2-3):479-92.

41. Nicolescu R, Petcu C, Cordeanu A, Fabritius K, Schlumpf M, Krebs R, et al. Environmental exposure to lead, but not other neurotoxic metals, relates to core elements of ADHD in Romanian children: performance and questionnaire data. Environ Res 2010;110:476-83.

42. Ha M, Kwon HJ, Lim MH, Jee YK, Hong YC, Leem JH, et al. Low blood levels of lead and mercury and symptoms of attention deficit hyperactivity in children: A report of the Children's Health and Environment Research (CHEER). Neurotoxicology 2009;30:31-6.

43. Debesa F, Budtz-Jørgensen E, Weihea P, Whited RF, Grandjean P. Impact of prenatal methylmercury exposure on neurobehavioral function at age 14 years. Neurotoxicol Teratol 2006;28(3):363-75.

44. Julvez J, Debes F, Weihe P, Choi A, Grandjean P. Sensitivity of continuous performance test (CPT) at age 14 years to developmental methylmercury exposure. Neurotoxicol Teratol 2010;32:627-32.

45. Myers GJ, Davidson PW, Cox C, Shamlaye CF, Palumbo D, Cernichiari E, et al. Prenatal methylmercury exposure from ocean fish consumption in Seychelles child development study. Lancet 2003;17(361):1686-92.

46. Centers for Disease Control and Prevention (CDC). Preventing lead poisoning in young children. Atlanta: CDC; 2005.

47. Bellinger DC. Very low lead exposures and children's neurodevelopment. Curr Opin Pediatr 2008;20(2):172-7.
48. Solon O, Riddell TJ, Quimbo SA, Butrick E, Aylward GP, Lou Bacate M, et al. Associations between cognitive function, blood lead concentration, and nutrition among children in the Central Philippines. J Pediatr 2008;152:237-43.

49. Nigg JT, Casey BJ. An integrative theory of attention-deficit/ hyperactivity disorder based on the cognitive and affective neurosciences. Dev Psychopathol 2005;17:785-806.

50. Castellanos FX, Sonuga-Barke EJ, Milham MP, Tannock R. Characterizing cognition in ADHD: Beyond executive dysfunction. Trends Cogn Sci 2006;10:117-23.

51. Froehlich TE, Lanphear BP, Auinger P, Hornung R, Epstein JN, Braun J, et al. Association of tobacco and lead exposures with attention-deficit/hyperactivity disorder. Pediatrics 2009;124(6):1054-63.

52. Wang HL, Chen XT, Yang B, Ma FL, Wang S, Tang ML, et al. Case-control study of blood lead levels and attention deficit hyperactivity disorder in Chinese children. Environ Health Perspect 2008;116:1401-6.

53. Roy A, Bellinger D, Hu H, Schwartz J, Ettinger AS, Wright RO, et al. Lead exposure and behavior among young children in Chennai, India. Environ Health Perspect 2009;117:1607-11.

54. Chiodo LM, Covington C, Sokol RJ, Hannigan JH, Jannise J, Ager J, et al. Blood lead levels and specific attention effects in young children. Neurotoxicol Teratol 2007;29(5): $538-46$.

55. Nigg JT, Knottnerus GM, Martel MM, Nikolas M, Cavanagh K, Karmaus W, et al. Low blood lead levels associated with clinically diagnosed attention-deficit/hyperactivity disorder and mediated by weak cognitive control. Biol Psychiatry 2008;63(3):325-31.

56. Nigg JT, Nikolas M, Knottnerus GM, Cavanagh K, Friderici K. Confirmation and extension of association of blood lead with attention-deficit/hyperactivity disorder (ADHD) and ADHD symptom domains at population - typical exposure levels. J Child Psychol Psychiatry 2010;51(1):58-65.

57. Cho SC, Kim BN, Hong YC, Shin MS, Yoo HJ, Kim JW, et al. Effect of environmental exposure to lead and tobacco 
smoke on inattentive and hyperactive symptoms and neurocognitive performance in children. J Child Psychol Psychiatry 2010;51(9):1050-7.

58. Kim Y, Cho SC, Kim BN, Hong YC, Shin MS, Yoo HJ.Association between blood lead levels $(<5 \mu \mathrm{g} / \mathrm{dl})$ and inattentionhyperactivity and neurocognitive profiles in school-aged Korean children. Sci Total Environ 2010;408(23):5737-43.

59. Bouchard M, Laforest F, Vandelac L, Bellinger D, Mergler D. Hair manganese and hyperactive behaviors: pilot study of school-age children exposed through tap water. Environ Health Perspect 2007;115(1):122-7.
60. Rodier J. Manganese poisoning in Moroccan miners. Br J Ind Med 1955;12:21-35.

61. Iregren A. Manganese neurotoxicity in industrial exposures: proof of effects, critical exposure level, and sensitive tests. Neurotoxicology 1999;20:315-23.

62. Levy BS, Nassetta WJ. Neurologic effects of manganese in humans: a review. Int J Occup Environ Health 2003;9:153-63.

63. Farias AC, Cunha A, Benko CR, McCracken JT, Costa MT, Farias LG, et al. Manganese in children with attention-deficit/ hyperactivity disorder: relationship with methylphenidate exposure. J Child Adolesc Psychopharmacol 2010;20:113-8.

This work is available in Open Access model and licensed under a Creative Commons Attribution-NonCommercial 3.0 Poland License - http://creativecommons.org/ licenses/by-nc/3.0/pl/deed.en. 